\title{
Aplicabilidade dos instrumentos de política urbana: o caso do plano diretor de São João da Barra - RJ
}

\author{
Ronaldo de Sousa Araújo ${ }^{1}$ \\ Juliana Landim Gomes Siqueira ${ }^{2}$ \\ Zélia Maria Peixoto Chrispim ${ }^{3}$
}

\section{RESUMO}

Este artigo apresenta um estudo sobre a utilização dos instrumentos da política urbana brasileira dispostos na Constituição Federal e no Estatuto da Cidade, tendo como objeto de análise o Plano Diretor e Lei de Uso e Ocupação do Solo do município de São João da Barra no estado do Rio de Janeiro. 0 objetivo do estudo é verificar a aplicabilidade dos instrumentos considerando a forma como eles são disponibilizados na legislação. A Metodologia utilizada foi de revisão bibliográfica, pesquisa documental e análise comparativa da legislação municipal com a legislação federal. Por meio de tabela, verificou-se a incidência dos instrumentos na legislação do município. Com a pesquisa verificou-se que a maioria dos instrumentos de política urbana dispostos na legislação de São João da Barra foram citados, mas não tiveram os locais de aplicação definidos, comprometendo a aplicabilidade destes instrumentos. A pesquisa reflete a dificuldade de consolidação da atual política urbana no país.

PALAVRAS-CHAVE: Estatuto da Cidade; Legislação urbana; Desenvolvimento urbano.

\section{ABSTRACT}

This manuscript presents a study on the use of Brazilian urban policy instruments set forth in the Federal Constitution and in the City Statute, having as object of analysis the City Plan and Land Use and Occupancy Law of the municipality of São João da Barra in the state of Rio de Janeiro. The objective of the study is to verify the applicability of the instruments considering how they are made available in the legislation. The Methodology used was bibliographic review, documentary research and comparative analysis of municipal legislation with federal legislation. By means of a table, it was verified the incidence of the instruments in the legislation of the municipality. With the research, it was verified that most of the urban policy instruments set forth in the legislation of São João da Barra were cited but did not have the application sites defined, compromising the applicability of these instruments. The research reflects the difficulty of consolidating the current urban policy in the country.

KEY-WORDS: City statute; Urban legislation; Urban development.

1 Ronaldo de Sousa Araújo: Arquiteto e urbanista pela UCG-GO; mestre em Gestão Urbanística e doutor em Gestão e Valoração Urbana pela UPC-Espanha; pós-doutorado em Gestão de Recursos Hídricos pelo ISTULisboa / UENF. Professor do Mestrado Profissional em Planejamento Regional e Gestão de Cidades da UCAMCampos; professor do Curso de Arquitetura e Urbanismo do Isecensa. Campos dos Goytacazes - RJ, Brasil. E-mail: r.saraujo@hotmail.com

2 Juliana Landim Gomes Siqueira: Administradora de Empresas pelo Isecensa; advogada pela FDC; especialista em Logística Portuária pelo Isecensa; professora dos cursos de Administração e de Engenharia de Produção do Isecensa; aluna do Mestrado Profissional em Planejamento Regional e Gestão de Cidades da UCAM-Campos. Campos dos Goytacazes - RJ, Brasil. E-mail: julianalandim_6@hotmail.com

3 Zélia Maria Peixoto Chrispim: Engenheira Civil pela UCG-GO; mestre em Geotecnia pela UENF; doutora em Geotecnia Ambiental pela UENF; doutorado sanduiche em Hidrogeologia pelo IST-ULisboa. Campos dos Goytacazes - RJ, Brasil. E-mail: zeliachrispim.100@gmail.com 


\section{Introdução}

Preocupada com os problemas urbanos no planeta, a ONU realizou no ano de $1976 \mathrm{em}$ Vancouver a primeira Conferência sobre Assentamentos Humanos - Habitat I. A segunda Conferência - Habitat II foi realizada em Istambul em 1996. Em 2016, considerando o fato de que a população mundial está concentrada em sua maioria nas áreas urbanas, $54 \%$ segundo dados das Nações Unidas (United Nations, 2015), e que são muitas as vantagens desta situação, mas que também são muitos os desafios, a ONU realizou a sua terceira Conferência sobre Habitação e Desenvolvimento Sustentável - Habitat III. Esta Conferência (United Nations, 2016) destacou a importância de "Regras e Regulamentos", "Planejamento Urbano e Design", e "Finanças Municipais" para a implementação da Nova Agenda Urbana. As Nações Unidas (UN-Habitat, 2017) observam que embora o processo de urbanização esteja vinculado ao desenvolvimento social e econômico, faltam em muitos países políticas e recursos humanos de apoio que possibilitem padrões sustentáveis de desenvolvimento.

A atual Política Urbana brasileira, formulada em décadas de discussão (Cardoso, 1997), foi estabelecida pela Constituição Federal de 1988 (Arts.182 e 183) e regulamentada pela Lei $n^{\circ}$ 10.257/2001 denominada Estatuto da Cidade (Brasil, 2001). Esta política, pelo período que está em vigor, já pode ser analisada enquanto a seus resultados e dificuldades. Este artigo analisa a aplicabilidade dos instrumentos de política urbana no plano diretor do município de São João Barra, estado do Rio de Janeiro.

Uma expectativa da política urbana brasileira foi que o plano diretor, fazendo uso dos demais instrumentos, conseguisse fazer frente à especulação imobiliária, possibilitando um aumento da oferta de terras urbanas no mercado, e com isso seriam diminuídos os valores dos imóveis. Neste propósito os instrumentos parcelamento e/ou edificação compulsórios, IPTU progressivo no tempo e desapropriação com pagamento em títulos da dívida pública teriam papel fundamental.

Entre as diretrizes gerais da política urbana estabelecida no Estatuto da Cidade (Art $.2^{\circ}$ ), cujo objetivo é ordenar o pleno desenvolvimento das funções sociais da cidade, está: "VI - ordenação e controle do uso do solo, de forma a evitar", entre outras coisas, "e) a retenção especulativa de imóvel urbano, que resulte na sua subutilização ou não utilização".

Após a aprovação do Estatuto da Cidade uma grande quantidade de planos diretores municipais foi aprovada. Muitos destes planos eram totalmente novos, e em outros casos houve revisão do plano anterior. A estas revisões dos planos diretores denominase modificações legais no planejamento urbanístico (Araújo, 2009).

A recente modificação legal no planejamento urbanístico do município de São João da Barra (Lei no 357/2015 que institui o Plano Diretor; Lei no 358/2015 que institui o Perímetro Urbano; e Lei $n^{\circ} 359$ que disciplina e ordena o Uso e Ocupação do Solo e dispõe sobre o Parcelamento do Solo), atendendo ao Estatuto da Cidade, dispôs sobre vários dos instrumentos da política urbana.

Ribeiro e Matos (2015) observaram que, em relação às principais lideranças dos setores público e privado na região existe um perfil sociocultural que inibe a ação coletiva no território, em que há dificuldade de integração dos atores e agentes. Por outro lado, devido a implantação do Porto do Açu e empresas do setor petrolífero, como demonstra Piquet e Oliveira (2016), as empresas transnacionais, com grande conhecimento técnico, estão cada vez mais presentes em São João da Barra.

Com a crise econômica recente houve uma diminuição de investimentos no empreendimento do Porto do Açu, localizado na cidade estudada e consequentemente isso 
refletiu na oferta de empregos diretos. Com a retomada da economia e dos investimentos, a expectativa é que aumente a demanda por habitação e, consequentemente, por infraestrutura e serviços públicos. Neste cenário o papel do planejamento urbano é fundamental. Espera-se que o plano diretor e os demais instrumentos de política urbana atendam as necessidades do município em relação à previsão e solução de problemas, assim como o desenvolvimento de potencialidades.

No Brasil, a distribuição dos Royalties do petróleo é um tema polêmico. Discute-se, entre outras coisas, se os recursos provenientes do petróleo têm sido bem aplicados. Este tema também é discutido em São João da Barra e região, e discute-se, inclusive, se a área desapropriada para a implantação do Distrito Industrial não foi maior que o necessário. Por outro lado, quase não se discute a utilização dos instrumentos do Estatuto da Cidade no Plano Diretor da cidade de São João da Barra.

Este artigo apresenta, em seções, um estudo sobre a utilização dos instrumentos de política urbana dispostos na Constituição brasileira e na Lei $n^{\circ}$ 10.257/2001 (Estatuto da Cidade), em que o objeto investigado é o Plano Diretor e a Lei de Uso e Ocupação do Solo do município de São João da Barra no Norte Fluminense. O estudo tem como propósito a verificação da aplicabilidade dos instrumentos, para tanto foi considerada a forma como eles são disponibilizados na legislação municipal. Como metodologia, buscou-se realizar revisão bibliográfica, pesquisa documental e análise da legislação municipal. Buscouse estudar a aplicabilidade dos instrumentos por meio da verificação na legislação da disponibilização de áreas na cidade para aplicação dos mesmos. Para a apresentação dos resultados foi utilizada uma tabela com indicação dos instrumentos citados na legislação e os que tiveram locais de aplicação definidos.

\section{Instrumentos de política urbana e sua aplicabilidade}

A política urbana brasileira, estabelecida pela Constituição federal de 1988 em seus artigos 182 e 183, está prestes a completar três décadas. Sua regulamentação em 2001 com a Lei $n^{\circ} 10.257$, denominada Estatuto da Cidade, já passa de uma década e meia. $\mathrm{O}$ Estatuto da Cidade (Brasil, 2001) disponibilizou uma série de instrumentos com o objetivo de ordenar o desenvolvimento das funções sociais da cidade e da propriedade (Art. $2^{\circ}$ ). Neste contexto foi atribuído ao plano diretor municipal um papel fundamental, pois é nele que devem conter as condições para a efetiva implementação desta política com a utilização dos instrumentos disponibilizados. Neste sentido, discute-se a aplicabilidade destes instrumentos considerando os planos diretores que têm sido aprovados no Brasil.

José Afonso da Silva (2002) observa que "aplicabilidade exprime uma possibilidade de aplicação". Segundo o autor, "se a norma não dispõe de todos os requisitos para sua aplicação aos casos concretos, falta-lhe eficácia, não dispõe de aplicabilidade".

Luís Roberto Barroso (2006) relaciona a eficácia da norma jurídica à produção dos efeitos jurídicos, sendo assim, para o autor, a eficácia jurídica está conectada a satisfação de todos os seus elementos, quais sejam: regulação dos atos que podem ocorrer entre os indivíduos, entre os indivíduos e o Estado e entre o Estado e os indivíduos. Dessa forma, para o autor, eficácia jurídica está ligada a executoriedade, aplicabilidade e exigibilidade das normas jurídicas, podendo, a norma ter eficácia jurídica sem ter eficácia social.

Logo após a aprovação do Estatuto da cidade já se observava que faltava para esta lei um maior detalhamento. Também faltava no Brasil a disponibilidade de técnicas de utilização destes instrumentos. Faltavam mais esclarecimentos sobre as possibilidades de formas de utilização dos instrumentos previstos (Araújo, 2001). Nestes últimos anos, 
estudos constataram que os instrumentos de política urbana previstos na legislação brasileira, foram previstos em muitas leis municipais, mas foram pouco regulamentados e aplicados (Araújo, 2009; Oliveira et al., 2013; Ministério das Cidades, 2015).

A falta de detalhamento de vários instrumentos previstos em lei, e a escassez de métodos e técnicas de aplicação disponíveis no Brasil, dificultou a aplicação dos mesmos. O almejado combate à especulação imobiliária, por exemplo, com a utilização do "parcelamento, utilização ou edificação compulsórios" e o "IPTU progressivo no tempo", não foi uma prática de sucesso nos municípios brasileiros em geral.

Vale destacar que, recentemente, estes dois instrumentos receberam do Ministério das Cidades (2015) um importante material que pode ajudar a reverter este quadro. Segundo este, o PEUC - Parcelamento, Edificação ou Utilização Compulsórios, juntamente com o IPTU Progressivo e com a Outorga Onerosa do Direito de Construir, são instrumentos urbanísticos que servem de base para que os municípios possam estruturar o planejamento urbano possibilitando a implementação de outras ferramentas do Estatuto da Cidade, e de projetos fundamentais para a cidade. O documento considera o PEUC uma ferramenta complexa, visto que, para sua aplicação são necessárias várias etapas, sendo essencial para viabilizar o cumprimento da função social da propriedade.

Segundo o documento do Ministério das Cidades (2015), as legislações de alguns países como Itália, França, Alemanha e Espanha, influenciaram na introdução do PEUC na legislação brasileira. Destas, a legislação espanhola foi a que mais influenciou. A lei de ordenamento do solo urbano de 1956 daquele país já determinava a obrigatoriedade de construir nos prazos estabelecidos nos planos ou projetos de urbanismo, sob pena de desapropriação ou venda forçada.

De acordo com a atual Lei do Solo e Reabilitação Urbana da Espanha, aprovada pelo Real Decreto Legislativo 7/2015 (Espanha, 2015), em caso de descumprimento da função social da propriedade e gestão do solo a Administração poderá fazer uso da desapropriação, aplicação da venda forçada ou substituição forçada (Art.49).

No Brasil, aos poucos, outros instrumentos também estão sendo objeto de maior atenção por parte do Ministério das Cidades como, Operação Urbana Consorciada (Ministério das Cidades, 2009) e Outorga Onerosa do Direito de Construir (Ministério da Cidades, 2012).

Villaça (2005) observa que instrumentos como Operação Urbana Consorciada, Outorga Onerosa, Transferência do Direito de Construir e até algumas categorias de Zonas Especiais de Interesse Social dependem da adesão do setor imobiliário. Mukai (2002) destaca que Operação Urbana Consorciada e Consórcio Imobiliário são importantes instrumentos para o desenvolvimento urbano.

Santin e Marangon (2008) chamam a atenção para a importância dos instrumentos Outorga Onerosa e Transferência do Direito de Construir para a proteção do patrimônio histórico. Os autores destacam a necessidade da regulamentação destes instrumentos pelo município para que proprietários de imóveis tombados possam "usufruir do benefício de poder transferir o potencial de construção daquele terreno (solo criado) para outro imóvel."

\section{0 contexto do município de São João da Barra, RJ}

São João da Barra (Figura 1) é um município com área de 455,04 km2 (IBGE, 2015), no Censo de 2000 foi registrada uma população de 27.682 habitantes, no Censo de 2010 a população era de 32.747 habitantes, e em 2016 a população estimada foi de 34.884 habitantes (IBGE, 2017). Com a descoberta de petróleo no final da década de 1970 o município passou a receber Royalties devido ao fato de ser limítrofe aos campos produtores de petróleo, e em 2000 passou definitivamente a ser produtor (São João da Barra, 2017). 
Figura 1 - Mapas de localização do município de São João da Barra, RJ.

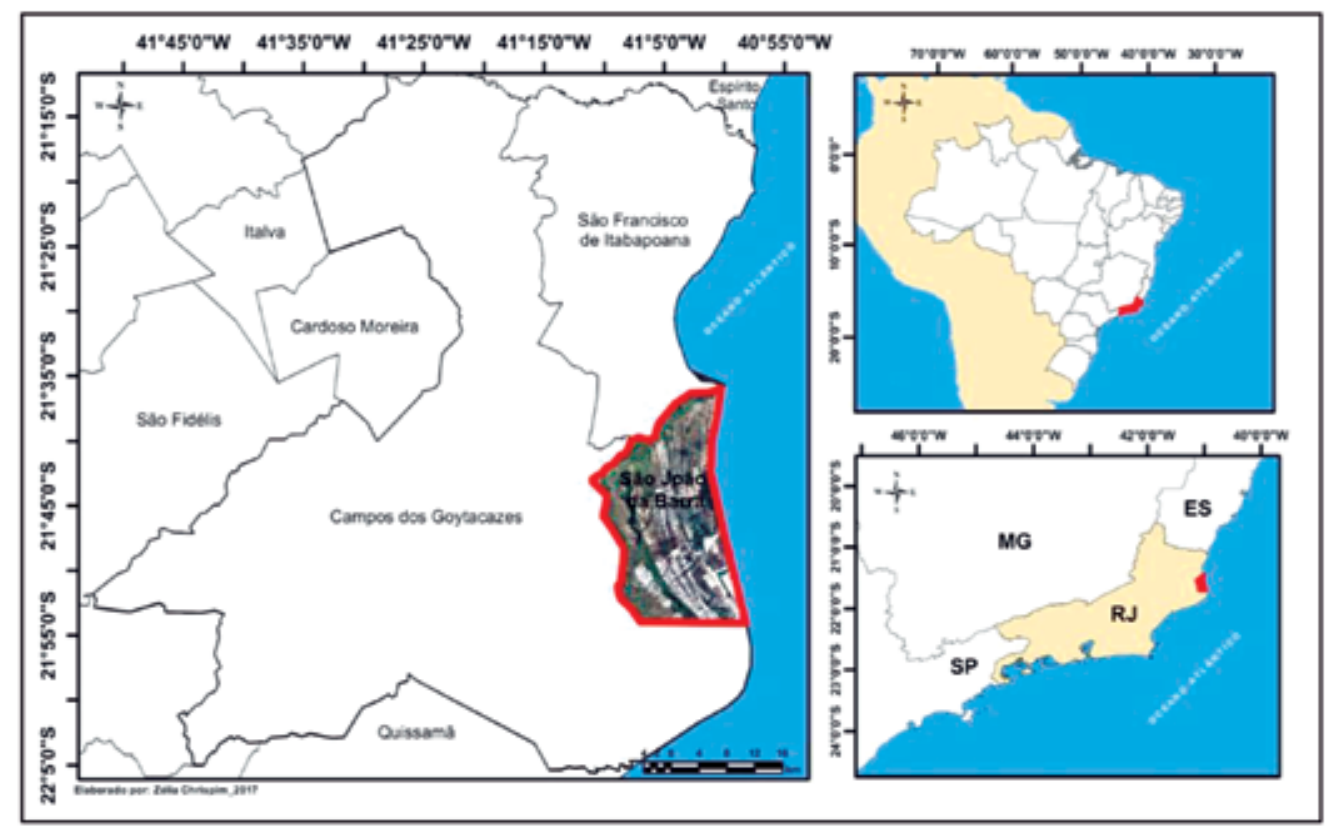

Fonte: Chrispim, 2017.

A arrecadação do município em Royalties do petróleo foi significativa a partir de 1999, chegando ao ápice em 2011 com um total de R $\$ 129.423 .982,34$. Mas nos últimos anos tem tido queda significativa. Em 2016 o município recebeu R\$ 64.043.647,63 de Royalties. (Info Royalties, 2017).

O mapa da Figura 2 demonstra que os municípios do Norte Fluminense apresentam os maiores percentuais de participação nos royalties de petróleo e gás do estado. O município de São João da Barra, por exemplo, está no nível quatro da escala, apresentando grande participação no recebimento de royalties.

Figura 2 - Mapa do percentual de participação dos municípios do Estado do Rio de Janeiro nos royalties totais.

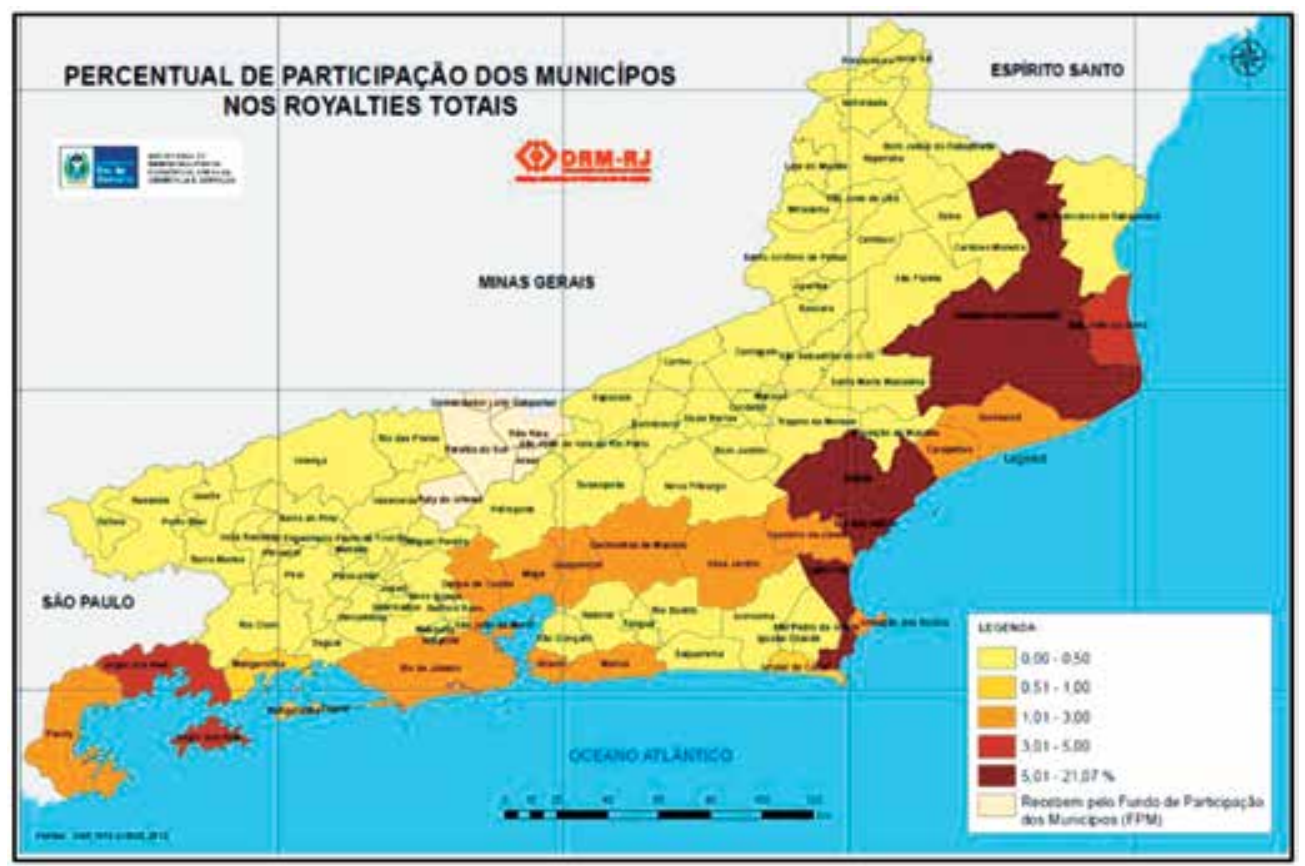

Fonte: Atlas da Distribuição de Royalties do Estado do Rio de Janeiro. Centro de Informações de Petróleo e Gás do ERJ-2012 apud Estudos Socioeconômicos dos Municípios do Estado do Rio de Janeiro do TCE, 2016. 
A arrecadação significativa dos royalties de petróleo gerou dependência em muitos municípios beneficiados. De acordo com o relatório de estudos socioeconômicos do município de São João da Barra de 2016 emitido pelo Tribunal de Contas do Estado do Rio de Janeiro, em muitos casos, as rendas petrolíferas se sobrepuseram à arrecadação própria dos tributos municipais, como o ISS, o IPTU e o ITBI (TCE / RJ, 2016).

Tratando-se especificamente de São João da Barra, o relatório emitido pelo Tribunal de Contas indica que a parcela de royalties e participações especiais variou entre $59 \%$ e $75 \%$ da receita total do município no período de 2010 a 2014, com queda em 2015, quando estas receitas representaram $51 \%$ em relação ao total arrecadado, como demonstra o gráfico na Figura 3.

Figura 3 - Gráfico da proporção dos royalties na receita total do município (R \$ mil) - 2010-2015.

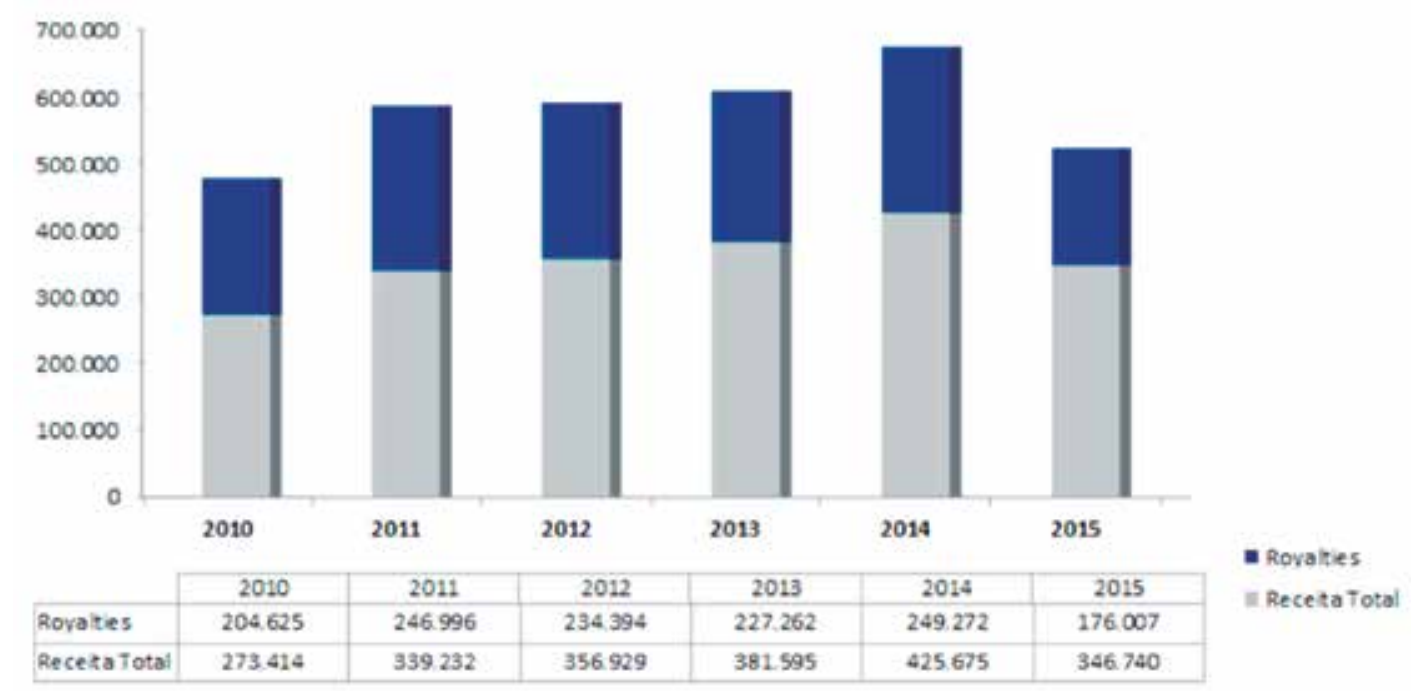

Fonte: Estudos Socioeconômicos dos Municípios do Estado do Rio de Janeiro do TCE, 2016.

Atualmente, o principal empreendimento do município é o Complexo Portuário do Açu, que está em operação desde 2014. No ano de 2016 o Complexo já recebeu 966 embarcações comerciais. O Porto do Açu abrange uma área de $90 \mathrm{~km} 2$ e está situado a $150 \mathrm{~km}$ da Bacia de Campos, possui $17 \mathrm{~km}$ de cais e $23 \mathrm{~m}$ de profundidade. O Porto conta também com um distrito industrial e uma retroárea para armazenamento e movimentação de carga (Prumo Logística, 2017).

De acordo com o Relatório de Impacto Ambiental - RIMA de 2011 (LLX; Ecologus; Agrar, 2011) a população estimada para 2025 para São João da Barra era de 410 mil habitantes e a de Campos dos Goytacazes correspondia a 834 mil habitantes, com isso previa-se que seria necessário a construção de 123 mil casas em São João da Barra e 103 mil em Campos dos Goytacazes. Da mesma forma, seria necessário sistema de captação, tratamento e distribuição de $0,7 \mathrm{~m} 3 / \mathrm{s}$ de água para abastecimento da população de São João da Barra e de 2,1 m3/s para Campos dos Goytacazes.

Apesar da grande expectativa em relação ao Porto do Açu, o crescimento populacional de São João da Barra e Campos dos Goytacazes está muito longe do que foi imaginado pelos atores envolvidos no processo de implantação do empreendimento. O resultado desta previsão exagerada de crescimento resultou em um processo especulativo na região, como o que foi observado por Rodrigues et al. (2010), em que os autores constataram que houve intensa procura por imóveis no início da implantação do empreendimento, mas diminuiu com o passar do tempo. 
O Plano Diretor de São João da Barra, Lei no 357/2015, se define como "um instrumento orientador e normativo dos processos de transformação da municipalidade nos aspectos socioeconômicos, urbanísticos, físico-ambientais e administrativos" (Art.2 ${ }^{\circ}$ ), e tem como finalidade orientar a atuação do poder público e da iniciativa privada, para tanto estabelece diretrizes e instrumentos visando o desenvolvimento sustentável assim como o atendimento dos desejos da sociedade (Art. $3^{\circ}$ ).

A Lei $n^{\circ}$ 359/2015, que disciplina e ordena o Uso e Ocupação do Solo e dispõe sobre o Parcelamento do Solo do Município, estabelece (Art.5) que o zoneamento é um instrumento técnico urbanístico tendo como objetivos fazer cumprir as funções sociais da cidade e da propriedade, e atribuir diretrizes específicas de uso e ocupação do solo para as zonas e setores estabelecidos.

No Mapa de Zoneamento de 2015 (Figura 4) pode-se observar as pequenas áreas já urbanizadas no município e uma considerável área para o crescimento da cidade, localizadas nas zonas mistas (ZM1 à ZM6)) e pelas áreas destinadas às atividades relacionadas ao Complexo Portuário do Açu (ZDE - Zona de Desenvolvimento Econômico, na cor cinza). Destacam-se também as Zonas Especiais de Interesse Ambiental (ZEIA 1 e ZEIA 2), Zonas de Ocupação Controlada (ZOC 1 e ZOC 2) e algumas Zonas Especiais de Interesse Social (ZEIS 1 e ZEIS 2). A terminologia "Zona Rural" não é utilizada neste mapa (que no caso é a área em branco) e tão pouco é citada na lei que trata do uso e ocupação do solo (Lei n 359/2015). Já o plano diretor (Lei n 357/2015) se refere a Macrozona Rural.

Figura 4 - Mapa de Zoneamento, 2015.

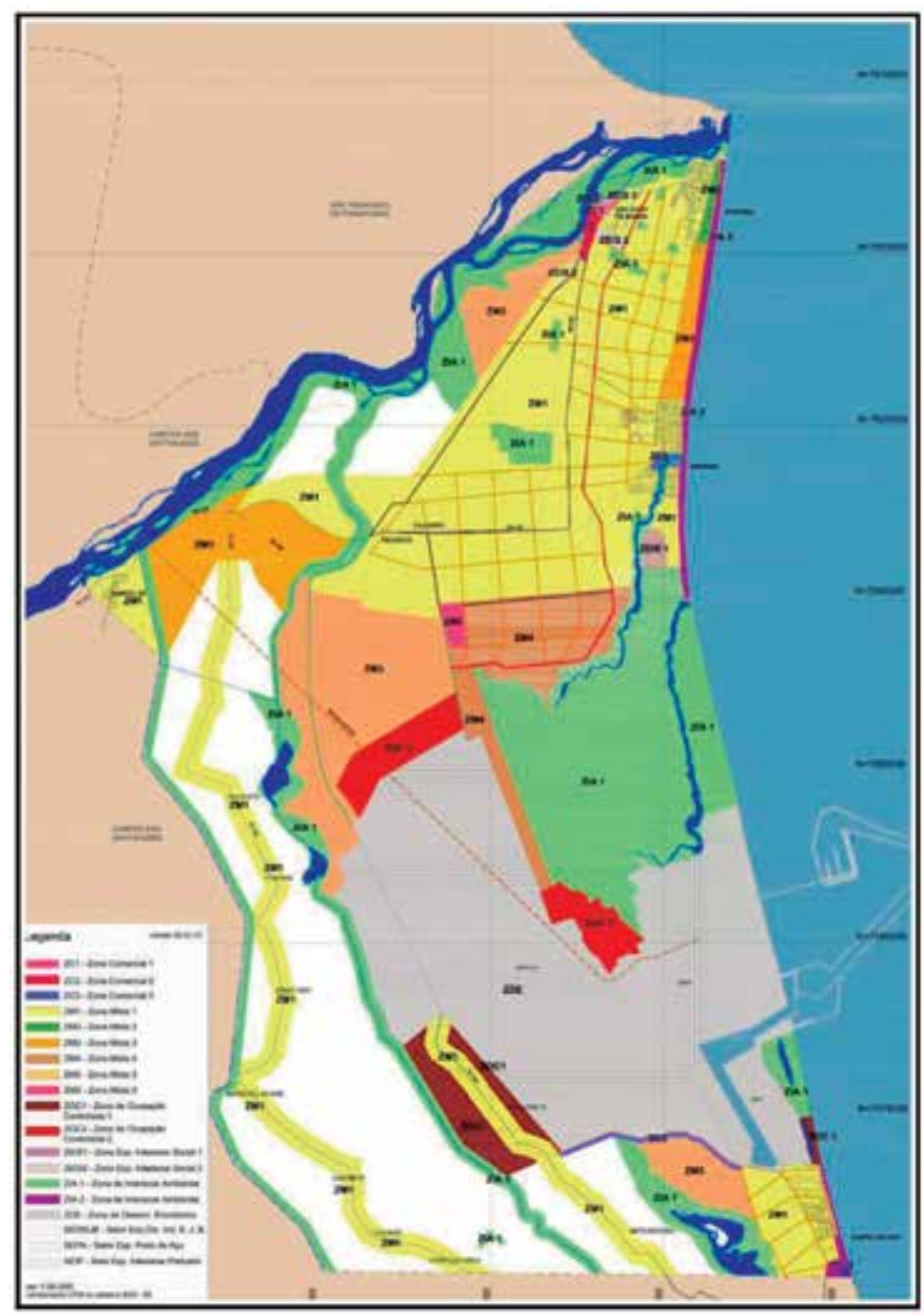

Fonte: Prefeitura Municipal de São João da Barra. 


\section{Aplicabilidade dos instrumentos de política urbana em São João da Barra}

Entre os aspectos a serem estudados no Plano Diretor do município de São João da Barra, instituído pela Lei $n^{\circ} 357 / 2015$, pode-se destacar: a influência das diretrizes do Estatuto da Cidade, a realidade do munícipio, e o Complexo Portuário do Açu. Neste estudo, procurou-se verificar a aplicabilidade do Estatuto da Cidade por meio da utilização dos instrumentos de política urbana no Plano Diretor desta cidade.

$\mathrm{Na}$ Tabela 1 verifica-se que a maioria dos instrumentos de política urbana foram citados no Plano Diretor, mas não tiveram área delimitada ou definida no território municipal para sua aplicação. Dos instrumentos que têm área definida para aplicação no território, o instrumento "Instituição de unidades de conservação" tem caráter ambiental, Estudo de Impacto de Vizinhança - EIV envolve diversos aspectos como, econômico, urbanístico e ambiental. Os instrumentos Zonas especiais de interesse social, Regularização fundiária, Assistência Técnica e Jurídica Gratuita, e Demarcação Urbanística tem forte preocupação social, mas são de caráter jurídico, econômico, arquitetônico e urbanístico.

Tabela 1 - Aplicação dos instrumentos do Estatuto da Cidade (Lei $\mathbf{n}^{\circ}$ 10.257/2001) no Plano Diretor (Lei $n^{\circ}$ 357/2015) e no Zoneamento do Uso e Ocupação do Solo e Parcelamento do Solo (Lei n $^{0}$ 359/2015) de São João da Barra

\begin{tabular}{|c|c|c|}
\hline Instrumento do Estatuto da Cidade & $\begin{array}{l}\text { Foi citado } \\
\text { na } \\
\text { legislaçẫo } \\
\text { municipal? }\end{array}$ & $\begin{array}{l}\text { Tem àrea defimitada } \\
\text { em mapa, ou foi } \\
\text { definido o local de } \\
\text { aplicaçāo? }\end{array}$ \\
\hline Parcelamento, edificaçào ou utilizaçào compulsórios & Sim & Năo \\
\hline IPTU progressivo no tempo & Sim & Năo \\
\hline $\begin{array}{l}\text { Desapropriaçio com pagamento em títulos da divida } \\
\text { pública }\end{array}$ & Sim & Nà̀ \\
\hline Usucapiāo especial de ímóvel urbano & Sim & Nå \\
\hline Usucapiào especial coletiva de imóvel urbano & Nào & Năo \\
\hline Contribuiçı̀o de melhoria & Sim & Năo \\
\hline Incentivos e beneficios fiscais $\mathrm{e}$ financeiros & Sim & Não \\
\hline Servidilo administrativa & Sim & Năo \\
\hline Tombamento de imóveis & Sim & Năo \\
\hline Instituição de unidades de conservaçào & Sim & Sim \\
\hline Zonas especiais de interesse social & Sim & $\operatorname{Sim}$ \\
\hline Concessĭo de direito real de uso & Sim & Năo \\
\hline Concessioo de uso especial para fins de moradia & Sim & Năo \\
\hline Direito de superficie & Nà̀ & Nao \\
\hline Direito de preempção & Sim & Não \\
\hline $\begin{array}{l}\text { Outorga onerosa do direito de construir e de alteraçlo } \\
\text { de uso }\end{array}$ & Sim & Nào \\
\hline Transferência do direito de construir & Sim & Não \\
\hline Operaçòes urbanas consorciadas & Sim & Năo \\
\hline Regularização fundiária & Sim & $\begin{array}{l}\operatorname{Sim} \\
\text { Nas ZEIS }\end{array}$ \\
\hline $\begin{array}{l}\text { Assistência técnica e juridica gratuita para as } \\
\text { comunidades e grupos sociais menos favorecidos }\end{array}$ & Sim & $\begin{array}{l}\text { Sim } \\
\text { Nas ZFIS }\end{array}$ \\
\hline $\begin{array}{l}\text { Demareaçåo urbanistica para fins de regularização } \\
\text { fundiária }\end{array}$ & Sim & $\begin{array}{c}\text { Sim } \\
\text { Demarcaçlo das ZEIS }\end{array}$ \\
\hline Legitimaçlo de posse & Não & Năo \\
\hline Estudo prévio de Impacto Ambiental (EIA) & Nào & Năo \\
\hline Estudo prévio de Impacto de Vizinhança (EIV) & Sim & $\begin{array}{c}\text { Sim } \\
\text { Tipos de } \\
\text { Emprecndimentos }\end{array}$ \\
\hline $\begin{array}{l}\text { Areas suscetiveis à ocorrência de deslizamentos de } \\
\text { grande impacto, inundaços bruscas ou processos } \\
\text { geológicos ou hidrológicos correlatos }\end{array}$ & Não & Nāo \\
\hline Consórcio imobiliário & Sim & Nāo \\
\hline Areas de risco & Sim & Naัo \\
\hline
\end{tabular}

Dos 27 instrumentos citados na tabela, por serem instrumentos que necessitam de definição de área para aplicação, 22 (81\%) foram citados na legislação e apenas 5 (19\%) não foram citados. No entanto, quando se analisa quantos instrumentos têm áreas 
delimitadas em mapa ou que foram definidos os locais de aplicação na legislação, verificase que apenas 6 (22\%) têm áreas definidas e 21 (78\%) não têm localizações definidas. Com os dados indicando que a grande maioria dos instrumentos que necessita de definição de área para aplicação não dispõe destas áreas, entende-se que o plano diretor de São João da Barra avançou muito pouco nos processos de aplicação destes instrumentos.

\section{Instrumentos do Estatuto da Cidade citados na Legislação de SJB}

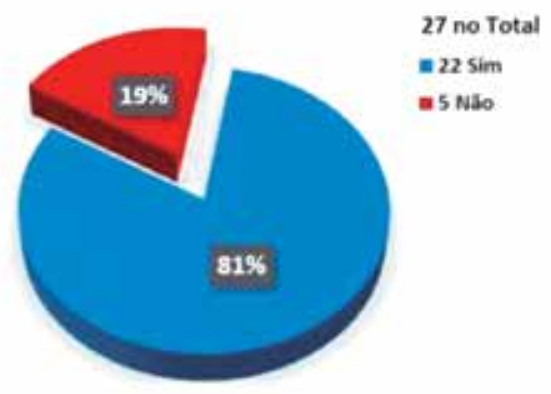

\section{Instrumentos do Estatuto da Cidade com localização definida}

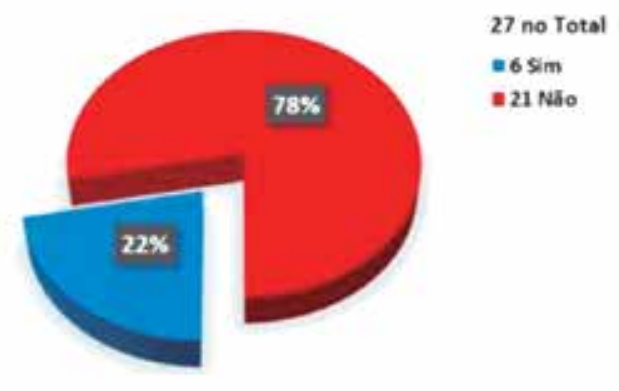

Os instrumentos Parcelamento, Edificação ou Utilização Compulsórios e IPTU Progressivo foram citados, mas não foram definidos locais de aplicação. São instrumentos de pouco interesse pelos municípios em geral, provavelmente por tratarem de uma questão extremamente polêmica, que é a retenção especulativa do solo. No Brasil, algumas limitações urbanísticas ao direito de propriedade já estão bastante consolidadas nas práticas urbanísticas (especialmente nos bairros centrais), como é o caso dos índices de aproveitamento do solo. No caso dos instrumentos da política urbana citados, confrontam o direito especulativo do imóvel resultando em dificuldade de aceitação pela sociedade. Isto ocorre, principalmente, pela pouca compreensão das possibilidades e formas de aplicação destes instrumentos. E o resultado é que não se visualiza os benefícios que a aplicação destes instrumentos pode proporcionar para a cidade e seus habitantes.

Como os instrumentos de política urbana não são autoaplicáveis, é necessário, além da citação no plano diretor e leis complementares: a definição dos locais de aplicação, as metodologias e os processos de aplicação além do que foi estabelecido no Estatuto da Cidade. Em São João da Barra, os instrumentos que tiveram mais atenção em relação a sua aplicação foram os relacionados com as Zonas Especiais de Interesse Social - ZEIS, Estudo prévio de Impacto de Vizinhança - EIA, e Instituição de Unidades de Conservação por meio de Zonas de Interesse Ambiental - ZIA.

Por outro lado, Zona Especial de Interesse Social foi citado na legislação e teve área definida no mapa de zoneamento. A Lei de Uso e Ocupação do Solo (Lei n. 359/2015) também definiu alguns critérios importantes para a aplicação deste instrumento, como a proteção ambiental, proibindo a demarcação de ZEIS em áreas de risco (Art.33). 0 aspecto ambiental também é destacado no Artigo 29 desta lei.

Art. 29. São objetivos da Zona Especial de Interesse Social:

I - efetivar o cumprimento das funções sociais da cidade e da propriedade assegurando a preservação, conservação e recuperação ambiental;

II - induzir os proprietários de terrenos vazios a investir em programas habitacionais de interesse social, de modo a ampliar a oferta de terra para a produção de moradia digna para a população de baixa renda; 
III - promover a regularização urbanística e fundiária dos assentamentos ocupados pela população de baixa renda;

IV - eliminar os riscos decorrentes de ocupações em áreas inadequadas ou, quando não for possível, reassentar seus ocupantes;

No processo de elaboração de um plano diretor é importante discutir, juntamente com a forma de aplicação dos instrumentos, o modelo de cidade que se pretende alcançar. Por exemplo, se será uma cidade com mais áreas verdes, o que a cidade precisa para fortalecer o processo de planejamento, e quais as estratégias para a população enfrentar o problema da especulação imobiliária.

\section{Discussão}

Em São João da Barra, assim como em muitos municípios brasileiros, como citado anteriormente, os instrumentos de política urbana foram pouco utilizados. Em estudos anteriores, Araújo (2009) observou que a não utilização de grande parte dos instrumentos de política urbana pelos planos diretores refletia a falta de eficácia da lei federal (Estatuto da Cidade) em relação à política urbana, pois a lei não disponibilizava elementos suficientes para a aplicação desta política.

A dificuldade de aplicação dos instrumentos acontece de forma generalizada em todo o Brasil. No estudo realizado pelo Ministério da Justiça (2015), verificou-se que poucos municípios no Brasil aplicaram os instrumentos PEUC - Parcelamento, Edificação ou Utilização Compulsórios (Goiânia, Maringá, Santo André, São Bernardo do Campo, São Paulo e Palmas) e IPTU Progressivo (apenas Maringá e São Bernardo do Campo).

A assistência técnica e jurídica gratuita para as comunidades e grupos sociais menos favorecidos está prevista no Plano Diretor de São João da Barra, mas não é definida a forma de efetivação desta atividade. No Brasil ainda são reduzidas as práticas neste sentido.

Depois de mais de uma década e meia da existência do Estatuto da Cidade, observa-se no Brasil a persistência de grandes problemas urbanos. Pouco se conseguiu em relação ao combate à especulação imobiliária e o problema da falta de moradia se agravou. Segundo levantamento do Censo Demográfico de 2010 (IBGE, 2013), foram registrados no Brasil a quantidade de 6.329 aglomerados subnormais, com 3.224 .529 domicílios e um total populacional de 11.425 .644 pessoas residentes nestas áreas, cerca de $6 \%$ da população brasileira. Segundo Pasternak e D'Ottaviano (2016), a questão das favelas assumiu uma dimensão sem precedentes na história, pois em 2000, o número de brasileiros vivendo nestas condições era de 6,5 milhões.

A política urbana, por meio do Estatuto da Cidade, não faz diferenciação da aplicação dos instrumentos previstos em relação ao porte dos municípios. Assim, tanto os municípios de pequeno, médio ou grande porte devem utilizar os mesmos instrumentos, conforme dispõe o Estatuto da Cidade. Evidentemente, os municípios menores têm mais dificuldades em utilizar os instrumentos, especialmente por questões técnicas, visto que geralmente os municípios menores são mais desprovidos de capacitação técnica que os maiores.

Segundo Rezende e Ultramari (2007), planejadores e gestores municipais, na prática urbana nacional, às vezes valorizam os instrumentos de planejamento outras vezes os esquecem. Segundo os autores, em um momento valoriza-se a estrutura municipal pública, e em outro valoriza-se os interesses públicos e a defesa dos interesses do setor 
privado. Como também são renovadas e alternadas as práticas de participação popular. Em determinado momento acredita-se na participação direta da população, em outro momento defende-se a estrutura da democracia representativa, e há momentos inclusive de adoção de posturas tecnocráticas.

A preferência por alguns instrumentos em detrimento de outros ocorre, muitas vezes, devido à dificuldade de entendimento e possibilidades do instrumento, assim como pela maior possibilidade de aceitação por parte da população. Instrumentos mais polêmicos são considerados pouco interessantes do ponto de vista político, é o caso do PEUC e IPTU progressivo no tempo. Instrumentos que, muitas vezes, são entendidos como uma violação ao direito de propriedade. Por outro lado, a criação de Zonas Especiais de Interesse Social tornasse bastante interessante considerando o grave problema social presente nas cidades brasileiras. No caso do município estudado, PEUC e IPTU progressivo foram citados no plano diretor mas não foram definidas áreas de aplicação dos mesmos, no entanto as Zonas Especiais de Interesse Social foram citadas no plano diretor e foram definidas as áreas de aplicação (Tabela 1).

O grande número de habitações subnormais no país exige um momento de avaliação da política urbana. Campos Filho (2001) observa que existem políticas "curativas" que se referem à eliminação dos déficits urbanos, e políticas "preventivas" que impedem o caos urbano. Assim, é importante avaliar os avanços, mas principalmente os fracassos da política urbana, especialmente no tocante à questão fundiária.

\section{Considerações finais}

Com esta pesquisa pôde-se verificar uma baixa utilização dos instrumentos de política urbana no plano diretor de São João da Barra, fato que não é isolado no Brasil, o que reflete a grande dificuldade de consolidação da atual política urbana e do processo de planejamento urbano no país.

O plano diretor de São João da Barra não dispõe de elementos suficientes para aplicação da maioria dos instrumentos da política urbana regulamentados pelo Estatuto da Cidade. Assim, pode-se afirmar que, de acordo com o que foi verificado, grande parte dos instrumentos de política urbana não é aplicável em São João da Barra. Neste sentido, o combate a especulação imobiliária com o barateamento do solo urbano fica comprometido, dificultando o acesso à terra das populações de baixa renda.

Em relação ao tema específico da delimitação de áreas para incidência dos instrumentos, deve-se levar em conta se a área de incidência do instrumento atende ou não sua função social definida no planejamento. Uma área caracterizada como vazio urbano é apropriada para a incidência dos instrumentos PEUC e IPTU progressivo no tempo, entretanto, esta mesma área também pode ser destinada para outro tipo de função, como Instituição de Unidades de Conservação. Este aspecto é importante considerar, pois além da grande demanda por habitação, as cidades brasileiras também carecem de áreas de interesse ambiental que são fundamentais para proporcionar qualidade de vida para a população.

A Constituição federal brasileira conferiu ao município a competência para realizar o seu planejamento urbano, no entanto, existe muita dificuldade para aplicação da política urbana e seus instrumentos. O Ministério das Cidades tem desempenhado um importante papel na tentativa de auxiliar os municípios no processo de planejamento urbano. Porém, ainda faltam muitas ações para se criar uma cultura urbanística e ambiental nos municípios, e com isso realizar transformações mais significativas.

Os temas urbanísticos e ambientais ainda são pouco discutidos pela população. As questões de ordem técnicas do planejamento urbanístico não são colocadas de forma 
mais ampla na mídia, impossibilitando maior entendimento destes temas por parte da população. Também faltam mais ações e investimentos para se estabelecer uma participação da população realmente voltada para a busca da cidade sustentável.

Para a utilização dos instrumentos da política urbana estabelecidos no Estatuto da Cidade é necessário que haja mais investimentos no desenvolvimento de métodos e técnicas de aplicação, como também maior esclarecimento da população em relação aos benefícios que estes instrumentos podem proporcionar para a cidade. O cidadão precisa discutir frequentemente como estes instrumentos de política urbana podem contribuir com a mudança da realidade de seu município. 


\section{Referências bibliográficas}

ARAÚjO, Ronaldo de Sousa. Considerações sobre o Estatuto da Cidade - Brasil (Lei $n^{\circ}$ 10.257/2001) e a Lei sobre o Regime do Solo e Ordenação Urbana - Espanha (Real Decreto Legislativo 1/1992). In: SANTOS, Thereza Carvalho (Org.). Tendências e desafios da integração do Brasil contemporâneo. Anais do Workshop Internacional de Dinâmicas Territoriais. Brasília: CIORD - UnB / AAP / ABM, 2001.

. Modificações no planejamento urbanístico: teoria e método de análise. São Paulo: Nobel, 2009.

BARROSO, Luís Roberto. A Nova Interpretação Constitucional. 2. ed. Rio de Janeiro: Renovar, 2006.

BRASIL. Lei nº. 10.257, de 10 de julho de 2001. Regulamenta os arts. 182183 da Constituição Federal e estabelece diretrizes gerais da política urbana e dá outras providências. Brasília, 2001.

ESPANHA. Real Decreto Legislativo 7/2015, de 30 de octubre, por el que se aprueba el texto refundido de la Ley de Suelo y Rehabilitación Urbana. BOE, Núm. 261. Sábado 31 de octubre de 2015. Sec. I Pág. 103232.

CARDOSO, Adauto Lúcio. Reforma urbana e planos diretores: avaliação da experiência recente. Cadernos IPPUR, Rio de Janeiro, Ano XI, Nos 1 e 2, 1997, p. 79-111.

IBGE - Instituto Brasileiro de Geografia e Estatística. Censo Demográfico 2010. Aglomerados Subnormais. Informações Territoriais. Rio de Janeiro: IBGE, 2013.

. 2016. Rio de Janeiro. São João da Barra.2016. Disponível em: http://cidades. ibge.gov.br/xtras/perfil.php?lang=\&codmun=330500\&search=rio-de-janeiro|sao-joaoda-barra. Acesso em: 03.05.2017.

INFO ROYALTIES. Indicadores. Disponível em: https://inforoyalties.ucam-campos.br/ informativo.php. Acesso em: 27/05/2017.

LLX; LOGUS; AGRAR. RIMA - Relatório de Impacto Ambiental. Infraestruturas do Distrito Industrial de São João da Barra. Maio/2011.

CAMPOS FILHO, Cândido Malta. Cidades brasileiras: seu controle ou o caos: o que os cidadãos devem fazer para a humanização das cidades no Brasil. São Paulo: Studio Nobel, 2001.

MINISTÉRIO DA JUSTIÇA. Parcelamento, edificação ou utilização compulsórios e IPTU progressivo no tempo: regulação e aplicação. Série Pensando o Direito, $\mathrm{n}^{\circ} 56$. Brasília: Ministério da Justiça / Secretaria de Assuntos Legislativos (SAL) / Ipea, 2015.

MINISTÉRIO DAS CIDADES. Operações urbanas: anais do seminário Brasil - França. Brasília: Ministério das Cidades, 2009.

. Outorga Onerosa do Direito de Construir: Caderno Técnico de Regulamentação e Implementação de Instrumentos do Estatuto da Cidade. Vol. 1. Brasília: Ministério das Cidades, 2012.

. Parcelamento, Edificação ou Utilização Compulsórios e IPTU progressivo no tempo: Caderno Técnico de Regulamentação e Implementação. Brasília: Ministério das Cidades, 2015.

MUKAI, Toshio. Direito urbano-ambiental brasileiro. São Paulo: Dialética, 2002.

OLIVEIRA, B.S.; SILVA, L.V.O.; SOARES, B.R. Uma análise dos instrumentos urbanísticos do Estatuto da Cidade no Plano Diretor de Rio Verde - GO. Caminhos de Geografia - revista online. Uberlândia, v.14, n.45 Mar/2013 p.183-192. 
PASTERNAK, S.; D’Ottaviano, C. Favelas no Brasil e em São Paulo: avanços nas análises a partir da Leitura Territorial do Censo de 2010. Cad. Metrop., São Paulo, v. 18, n. 35, pp. 75-99, abr 2016. http://dx.doi.org/10.1590/2236-9996.2016-3504.

PIQUET, Rosélia; OLIVEIRA, Claudia. A presença de empresas transnacionais no Norte Fluminense. Cadernos do Desenvolvimento Fluminense $N^{\circ}$ 9, Rio de Janeiro, pp. 3947, jan/jun 2016.

PRUMO LOGÍSTICA. O empreendimento. Disponível em: http://www.prumologistica. com.br/pt/superporto-do-acu/Paginas/o-empreendimento.aspx. Acesso em: 17/05/2017.

REZENDE, Dênis Alcides; ULTRAMARI, Clovis. Plano diretor e planejamento estratégico municipal: introdução teórico-conceitual. RAP. Rio de Janeiro 41(2):255-71, Mar./Abr. 2007.

RIBEIRO, Alcimar das Chagas; MATOS, Elza M. Gonçalves Campos. Desafios do território em transformação: O Complexo Portuário do Açu e seus reflexos socioeconômicos. Cadernos do Desenvolvimento Fluminense, n. 6. Rio de Janeiro: CEPERJ, 2015.

RODRIGUES, Luana do Amaral; PALMEIRA, Daniel Trindade; LEMOS, Linovaldo Miranda. Impactos sócioterritoriais da implantação do Porto do Açu. Anais XVI Encontro Nacional de Geógrafos. Porto Alegre: 25-31 julho, 2010.

SANTIN, Janaína Rigo; MARANGON, Elizete Gonçalves. O Estatuto da Cidade e os instrumentos de política urbana para proteção do patrimônio histórico: outorga onerosa e transferência do direito de construir. HISTÓRIA, São Paulo, 27 (2): 2008.

SÃO JOÃO DA BARRA. Lei $N^{\circ}$ 357/2015, de 25 de maio de 2015. Institui o Plano Diretor do município de São João da Barra e dispõe sobre o macrozoneamento do município. Câmara Municipal de São João da Barra, 2015.

$17 / 05 / 2017$.

Histórico. Disponível em: http://www.sjb.rj.gov.br/historico. Acesso em:

SILVA, José Afonso da. Aplicabilidade das Normas Constitucionais. São Paulo: Malheiros, 2002.

TCE / RJ - Tribunal de Contas do Estado do Rio de Janeiro. Estudos Socioeconômicos dos Municípios do Estado do Rio de Janeiro - São João da Barra. Rio de Janeiro: TCE / RJ, 2016.

UN-HABITAT. National Urban Policies. Disponível em: https://unhabitat.org/urbaninitiatives/initiatives-programmes/national-urban-policies/. Acesso em: 07/06/2017.

UNITED NATIONS. World Urbanization Prospects: The 2014 Revision. United Nations Department and Social Affairs / Population Division. New York, 2015.

Habitat III. The New Urban Agenda. 2016. Disponível em: http://habitat3. org/the-new-urban-agenda. Acesso em: 07/06/2017.

VILLAÇA, Flávio. As ilusões do plano diretor. São Paulo, 2005. 